\title{
Investigation on the atomic structural evolution of as-prepared and annealed $\mathrm{ZrCuAl}$ metallic glasses
}

\author{
Liang Yang, ${ }^{\text {a) }}$ Cai-Long Huang, and Gu-Qing Guo \\ College of Materials Science and Technology, Nanjing University of Aeronautics and Astronautics, \\ Nanjing 210016, People's Republic of China
}

(Received 1 October 2011; accepted 6 January 2012)

\begin{abstract}
Atomic structures of the $\mathrm{Zr}_{48} \mathrm{Cu}_{45} \mathrm{Al}_{7}$ as-prepared and annealed metallic glasses (MGs) were investigated by performing the reverse Monte Carlo simulation on the synchrotron radiation-based experiments. It was found that although the annealed sample remains completely amorphous, the volumes of the Al-centered clusters evidently expand, which is attributed to the relatively longer $\mathrm{Al}-\mathrm{Zr}$ bonds. As a result, the role of $\mathrm{Al}$ atoms as the glue atoms to connect and fix the $\mathrm{Zr}$ - and $\mathrm{Cu}$-centered large clusters is accordingly weakened, which leads to the ease of the rearrangement of atoms and clusters in the glass state. This study provides an insight into the microstructures of MGs, which extends understanding of the structural evolution in the glass alloys during annealing prior to the precipitation of nanocrystals.
\end{abstract}

\section{INTRODUCTION}

As a class of amorphous materials, the metallic glasses (MGs) have been attracting increasing interest in recent years because they possess scientific and engineering significance due to their unique properties. ${ }^{1,2}$ Unfortunately, these MGs have encountered a challenge to be widely used in engineering because of their limited casting size, unsolved problem about the glass-forming mechanism, expensive cost, and so on. ${ }^{1}$ However, it is found that the precipitation of nanocrystals in the amorphous alloys can improve their properties, ${ }^{3}$ such as the good soft magnetic property ${ }^{4}$ and high strength, ${ }^{5}$ which may extend their application as engineering materials. Therefore, vast efforts have been devoted to searching for the relationship between the amorphous/nanocrystal structure and their unique properties. ${ }^{6-10}$ So far, amorphous/nanocrystal composite materials can be prepared via the thermal synthesis, ${ }^{11}$ the mechanical processing, ${ }^{12}$ and the electron irradiation ${ }^{13}$ upon MGs. In particular, as a thermal synthesis method, annealing treatment was largely used to prepare these materials, which also is available for probing the phase transformation kinetics and mechanism of the nanocrystallization in amorphous alloys. ${ }^{14-16}$ Whereas, the structural evolution of amorphous-to-nanocrystallization change is far from being clarified, especially whether and how structural evolution occurs in the glasses during annealing prior to the precipitation of nanocrystals is a long-standing issue. ${ }^{17}$ In this work, a series of state-of-the-art synchrotron radiationbased experiments coupled with simulations were performed to address this issue, by investigating the structural

\footnotetext{
a) Address all correspondence to this author.

e-mail: yangliang@nuaa.edu.cn

DOI: $10.1557 /$ jmr.2012.14
}

evolution of the $\mathrm{Zr}_{48} \mathrm{Cu}_{45} \mathrm{Al}_{7}$ amorphous alloy, ${ }^{18}$ which is a representative bulk MG with unique engineering and structural significance.

\section{EXPERIMENTS AND SIMULATIONS}

The $\mathrm{Zr}_{48} \mathrm{Cu}_{45} \mathrm{Al}_{7}$ alloy ingot was prepared by arc-melting the mixtures of $\mathrm{Cu}(99.9 \mathrm{wt} \%), \mathrm{Zr}(99.9 \mathrm{wt} \%)$, and $\mathrm{Al}$ (99.9 wt\%) elements in Ti-gettered high-purity argon atmosphere, which was melted at least five times to ensure its compositional homogeneity. The corresponding amorphous ribbons with a cross section of $0.04 \times 2 \mathrm{~mm}^{2}$ were obtained from the master alloys by single-roller melt spinning at a wheel surface velocity of $40 \mathrm{~m} / \mathrm{s}$ in purified Ar atmosphere. Then, the annealing treatment was carried out in an oven with a vacuum of $10^{-4} \mathrm{~Pa}$ at $598 \mathrm{~K}$ for $3 \mathrm{~min}$. This temperature is much lower than its glass transition temperature $(708 \mathrm{~K}) .{ }^{18}$ Subsequently, the synchrotron radiation-based high-energy (about $100 \mathrm{keV}$ ) x-ray diffraction measurements were performed upon the as-prepared and annealed $\mathrm{ZrCuAl}$ samples at the beam line, BW5, at HASYLAB (Hamburg, Germany). The two-dimensional diffraction data were recorded using a Mar345 image plate. In addition, using the transmission mode, their $\mathrm{Zr}$ and $\mathrm{Cu} \mathrm{K}$ edge extended $\mathrm{x}$-ray absorption fine structure (EXAFS) spectra also were measured at the beam line, BL14W1, in the Shanghai Synchrotron Radiation Facility of China. EXAFS did not allow to measure the Al-centered local structure because of the rather low and experimentally inaccessible energy value of the $\mathrm{Al}$ K-edge $(1.560 \mathrm{keV})$. Both of the diffraction patterns and EXAFS spectra were normalized via a standard data reduced procedure, ${ }^{19}$ employing the softwares PDFgetX and VIPER, respectively. To ensure the reliability of the deduced atomic structural information, both of the normalized diffraction and EXAFS 
data were simulated simultaneously under the framework of reverse Monte Carlo (RMC). ${ }^{20,21}$ Two cubic boxes containing 40,000 atoms were built to simulate these two sample sets, matching the selected $\mathrm{Zr}_{48} \mathrm{Cu}_{45} \mathrm{Al}_{7}$ composition. Finally, both of the simulated atomic structural models were further analyzed by the Voronoi tessellation method. ${ }^{22,23}$

\section{RESULTS AND DISCUSSION}

Figures 1(a) and 1(b) show the experimental structural factor $S(Q)$ obtained from the diffraction measurement, $\mathrm{Zr}$ and $\mathrm{Cu} \mathrm{K}$-edge EXAFS data of the as-prepared and annealed $\mathrm{Zr}_{48} \mathrm{Cu}_{45} \mathrm{Al}_{7}$, along with their corresponding simulated curves. Except for the first strong peak, the smooth experimental $S(Q)$ curves exhibit the gentle oscillations, and with no sharp peaks, which indicate the full amorphous nature in both samples. The plots of their experimental $S(Q)$ and $\mathrm{Cu}$ EXAFS curves are almost the same. However, a slight $\mathrm{k}$-shift and intensity difference of the oscillations between the experimental Zr EXAFS data of both samples are observed, which suggest that the local structure around the $\mathrm{Zr}$ atoms changes when the annealing treatment is performed on the $\mathrm{ZrCuAl}$ MG. To get more direct structural information, the partial pair distribution function $G(r)$ s are deduced and plotted in Fig. $2(\mathrm{Cu}-\mathrm{Cu}$, $\mathrm{Cu}-\mathrm{Al}$, and $\mathrm{Al}-\mathrm{Al} G(r)$ s are not shown here). It is found that there is no obvious difference in the $\mathrm{Zr}-\mathrm{Zr}, \mathrm{Zr}-\mathrm{Cu}$, $\mathrm{Cu}-\mathrm{Cu}, \mathrm{Cu}-\mathrm{Al}$, and $\mathrm{Al}-\mathrm{Al} G(r) \mathrm{s}$ for both samples. However, an evident discrepancy ranged from 2.2 to $3.5 \AA$ is observed in the first-shell distribution (FSD) of the $\mathrm{Zr}-\mathrm{Al}$ pair, which is highlighted in the inset. The FSD is split into two subpeaks (S1 and S2) in the as-prepared $\mathrm{ZrCuAl}$, which possess the peak values at 2.55 and $3.00 \AA$, respectively. However, in the annealed sample, the FSD is mainly attributed to the relatively strong $\mathrm{S} 1$ peak, whose peak value shifts to a higher value $(2.70 \AA)$, and the intensity of the $\mathrm{S} 2$ subpeak is much lower. It indicates that compared with those of the as-prepared $\mathrm{ZrCuAl}$, most of the $\mathrm{Zr}-\mathrm{Al}$ pairs possess the similar and longer bond length $(2.70 \AA)$ in the annealed sample, leading to the change of the short-range ordering. In addition, because the concentration of $\mathrm{Zr}$ around $\mathrm{Al}$ is much higher than that of $\mathrm{Al}$ around $\mathrm{Zr}$, it is suggested that the change of the $\mathrm{Al}$-centered local ordering is more obvious than that of the $\mathrm{Zr}$-centered counterpart.

To further address this issue, the RMC-simulated atomic structural model is further analyzed at the cluster scale. Figures 3(a)-3(c) show the Zr-, Cu-, and Al-centered major Voronoi tessellation clusters, which have the broad distributions with the coordination numbers ranged from 8 to 14 . A slight tendency is observed compared with those in the as-prepared $\mathrm{ZrCuAl}$, the large $\mathrm{Al}$-centered clusters (such as $<0,2,8,2>,<0,2,8,1>$ ) possess the relatively high weights in the annealed sample, and the small Al-centered ones (such as $\langle 0,3,6,0\rangle$ and $\langle 0,4,4,1\rangle$ ) have the lower
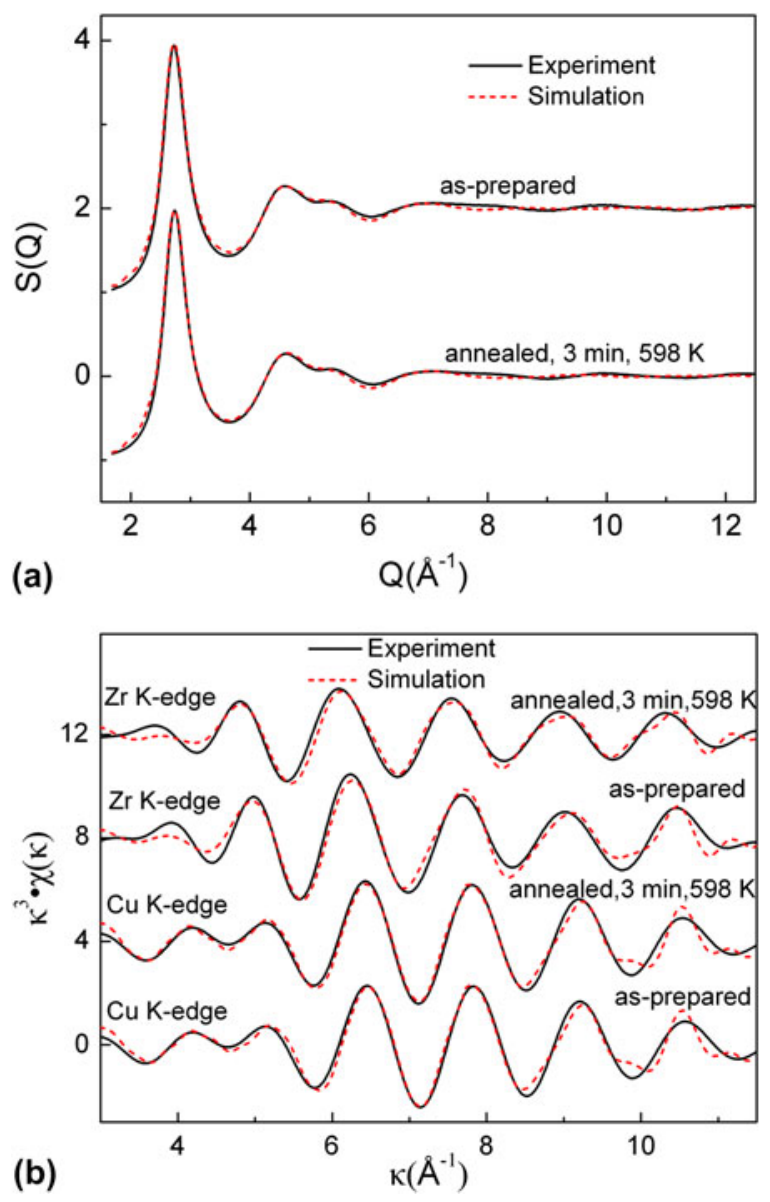

FIG. 1. (a) Structure factor $S(Q)$ and (b) $\mathrm{Zr}$ and $\mathrm{Cu}$ K-edge extended $\mathrm{X}$-ray absorption fine structure spectra in the as-prepared and annealed $\mathrm{Zr}_{48} \mathrm{Cu}_{45} \mathrm{Al}_{7}$ metallic glasses. The solid and dotted lines denote the experimental and simulation data, respectively.

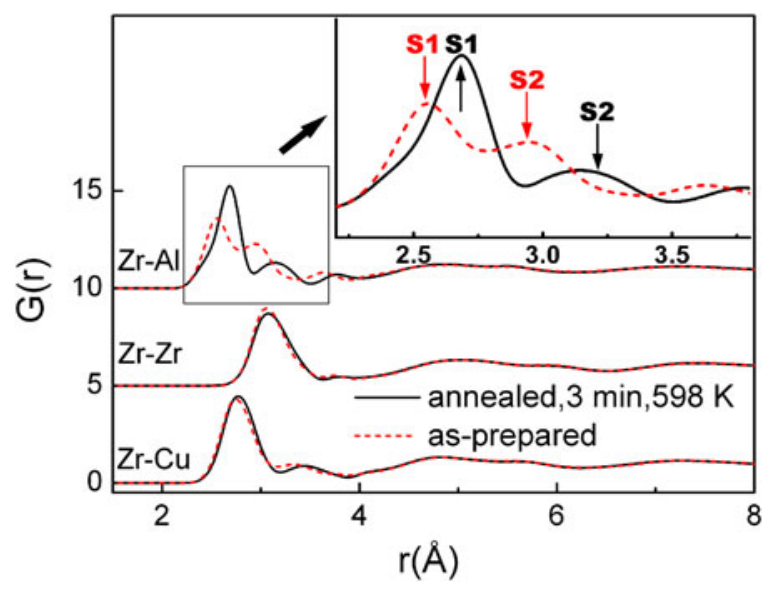

FIG. 2. Partial pair distribution function $G(r) \mathrm{s} . \mathrm{Zr}-\mathrm{Al}, \mathrm{Zr}-\mathrm{Zr}$, and $\mathrm{Zr}-\mathrm{Cu}$ pairs are plotted here. The dotted and solid lines stand for the as-prepared and annealed samples, respectively.

fractions. Such a tendency is not obvious in the distributions of $\mathrm{Zr}$ - or $\mathrm{Cu}$-centered clusters. It also indicates that the structural evolution mainly starts around the $\mathrm{Al}$ atoms when 

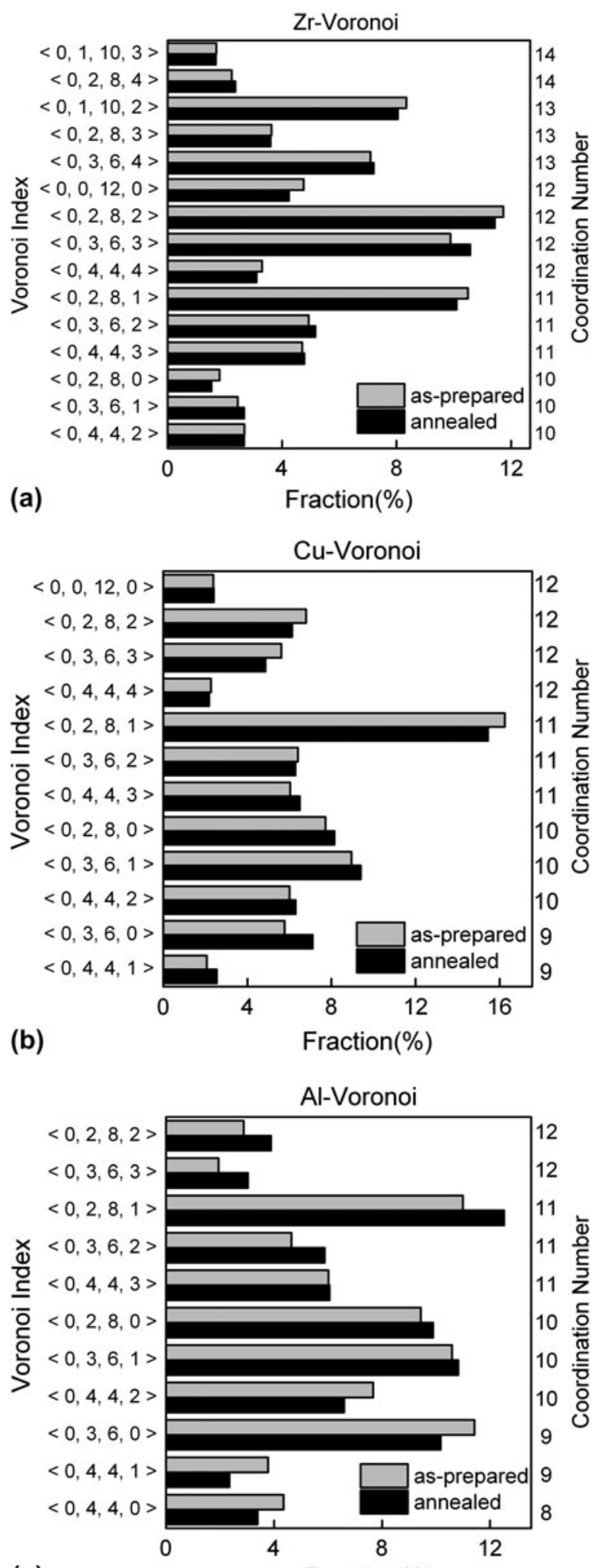

(c)

Fraction(\%)

FIG. 3. Distribution of the major Voronoi clusters centered with (a) $\mathrm{Zr}$, (b) $\mathrm{Cu}$, and (c) $\mathrm{Al}$ atoms.

the glassy alloy is under annealing. Moreover, the volumes of the random atom-centered clusters are calculated for both samples, whose distributions are plotted in Fig. 4(a). It is
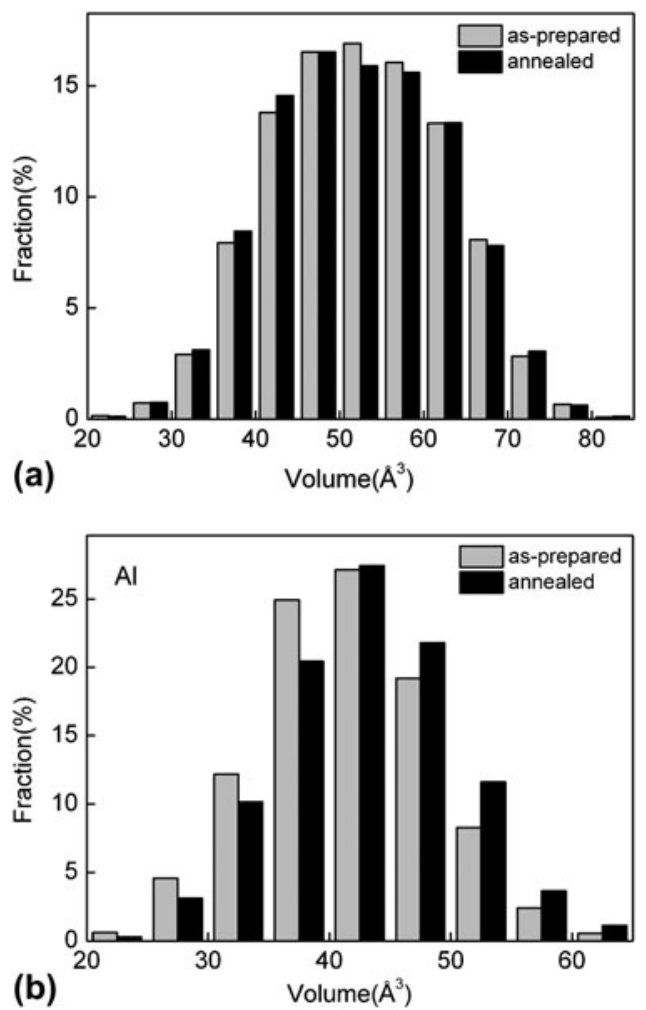

FIG. 4. Distribution of the volumes of the Voronoi clusters centered with (a) a random atom and (b) an $\mathrm{Al}$ atom.

shown that there is no statistical change in the volume distributions, which means that on average, the present annealing leads no obvious change in the local structural ordering. Nevertheless, the random atom-centered clusters cannot be regarded as the backbones of glassy structure, while the solute-centered clusters are recognized as the basic building blocks to enable the formation of the short-tomedium range ordering. ${ }^{24,25}$ The $\mathrm{Al}$ atoms should be the solutes considering its relatively low concentration in both samples, thus, the volumes of the Al-centered clusters also are calculated and plotted in Fig. 4(b). It is worth noting that the large clusters (with a volume larger than $50 \AA^{3}$ ) have the relatively high weights in the annealed sample, which indicates that the annealing treatment leads to the expansion of the Al-centered clusters. We have revealed that the average $\mathrm{Zr}-\mathrm{Al}$ bond length is longer in the annealed $\mathrm{ZrCuAl}$ MG than that of the as-prepared sample, which should be the origin of the volume expansion in the Al-centered clusters.

In addition, we compared the representative clusters in the annealed sample with those deduced from the possible precipitated nanocrystalline phases after annealing, ${ }^{26,27}$ as plotted in Figs. 5(a) and 5(b). The method to extract clusters in crystal phases refers to our previous work. ${ }^{28}$ It is shown that the Voronoi tessellation clusters in Fig. 5(a) are closed convex polyhedra formed by a set of Delaunay tetrahedra with the common vertex at their center atoms, and their surfaces should be only made up of triangle faces. ${ }^{29}$ These 

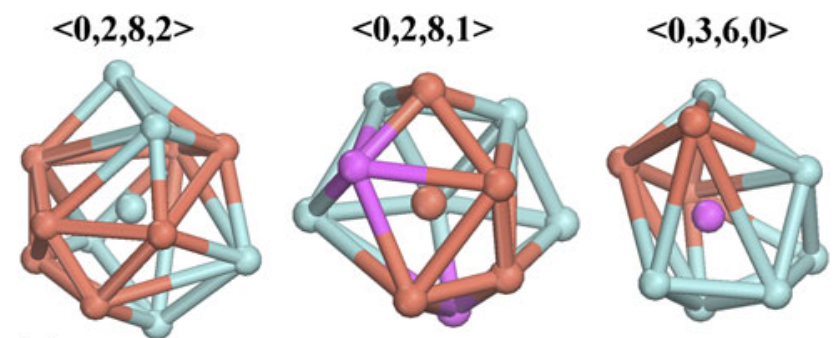

(a)
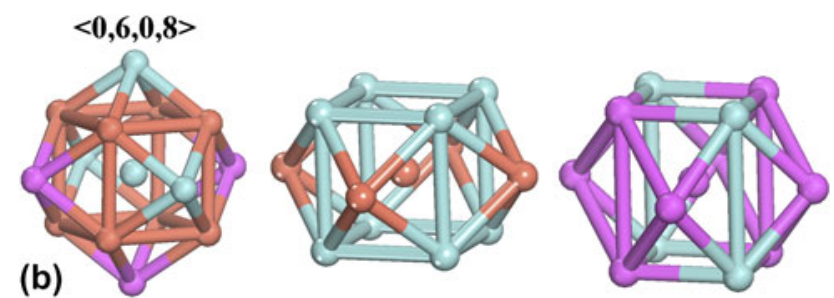

FIG. 5. Configurations of some representative clusters from (a) the annealed sample and (b) the possible precipitated nanocrystalline phases after annealing. The blue, red, and purple spheres represent the $\mathrm{Zr}, \mathrm{Cu}$, and $\mathrm{Al}$ atoms, respectively. In particular, in (b), the left, the center, and the right are the clusters extracted from the $\mathrm{AlCu}_{2} \mathrm{Zr}$, the $\mathrm{CuZr}_{2}$, and the $\mathrm{Al}_{3} \mathrm{Zr}$ crystal phases, respectively. Not all the clusters extracted from the glass alloy and the crystal phases are shown here.

clusters have abundant 5-fold-rotation symmetry features, which are favored in the glass state. ${ }^{30}$ However, most of the clusters extracted from the crystals cannot be indexed using the Voronoi tessellation method because their surfaces are made up of the quadrangles beside the triangles. Although the others have the Voronoi tessellation indexes, they are rarely found in the glasses, such as the $<0,6,8,0\rangle$ cluster illustrated in Fig. 5(b). It indicates that the clusters in the annealed glass are different with those in the crystal alloys, i.e., the transition of the glass-favored clusters to those favored in corresponding crystals is absent.

In our previous work, ${ }^{31}$ it has been suggested that in the as-prepared $\mathrm{ZrCuAl} \mathrm{MG}$, the relatively short $\mathrm{Zr}-\mathrm{Al}$ bond attributing from their strong atomic interaction leads to formation of the relatively small and compact Al-centered clusters in the as-prepared $\mathrm{ZrCuAl}$ MG. These $\mathrm{Al}$ atoms can be regarded as the glue atoms, which occupy the interstices around the $\mathrm{Zr}$ - and $\mathrm{Cu}$-centered large clusters to connect and fix them. Accordingly, it strengthens the glassy structure to bypass the crystallization during quenching. It is the structural origin of the enhanced glass-forming ability in the $\mathrm{ZrCu}$ alloys with the $\mathrm{Al}$ microalloying element. In the present work, it is revealed that compared with that of the as-prepared sample, the $\mathrm{Zr}-\mathrm{Al}$ pair of the annealed $\mathrm{ZrCuAl}$ has a longer bond length, which indicates that the $\mathrm{Al}-\mathrm{Zr}$ atomic interaction is relatively weakened, and, accordingly, the neighbor atoms are relatively loosely packed around the $\mathrm{Al}$ centers to form clusters with the larger volumes. Although in the present annealed sample, the direct transition of the glass-favored clusters to those favored in corresponding crystals is absent, the expansion of the Al-centered clusters leads to the enhanced motility of $\mathrm{Al}$ atoms and their neighbor atoms. The role of $\mathrm{Al}$ atoms as the glue atoms to connect and fix the $\mathrm{Zr}$ - and $\mathrm{Cu}$-centered large clusters is accordingly weakened, i.e., it decreases the stability of the cluster favored in the glass state. We suppose that once more energy is provided during annealing, the clusters are more unstable and prone to collapse or transform into the crystal-favored clusters, leading to the precipitation of nanocrystal in the amorphous alloys.

\section{CONCLUSIONS}

In summary, the atomic structural evolution of the as-prepared and annealed $\mathrm{ZrCuAl}$ MGs is investigated. It is revealed that the $\mathrm{Zr}-\mathrm{Al}$ pair has a longer bond length in the annealed $\mathrm{ZrCuAl}$ sample, which is attributed from their relatively weakened atomic interaction. It leads to expansion of the Al-centered clusters. Thus, the motility of the $\mathrm{Al}$ atoms and their neighbor atoms are increased, which decreases the connection and stability of their neighbor $\mathrm{Zr}$ - and $\mathrm{Cu}$-centered clusters. Thus, it may ease the rearrangement of clusters and atoms in the glass state. The present work not only addresses the issue that how the microstructure changes in MGs during annealing but also has implication for understanding on the mechanism of the precipitation of nanocrystals in glassy alloys.

\section{ACKNOWLEDGMENTS}

The authors thank the HASYLAB in Germany and the Shanghai Synchrotron Radiation Facility in China for the use of the advanced synchrotron radiation facilities. Financial supports from the National Natural Science Foundation of China (Grant No. 10805027), the Natural Science Foundation of Jiangsu Province (Grant No. BK2011071), and the NUAA Research Funding (Grant No. NS2010168) are gratefully acknowledged.

\section{REFERENCES}

1. A. Inoue: Stabilization of metallic supercooled liquid and bulk amorphous alloys. Acta Mater. 48, 279 (2000).

2. W.H. Wang, C. Dong, and C.H. Shek: Bulk metallic glasses. Mater. Sci. Eng., R 44, 45 (2004).

3. A.L. Greer: Metallic glasses. Science 267, 1947 (1995).

4. Y. Yoshizawa, S. Ogurna, and K. Yamauchi: New Fe-based soft magnetic alloys composed of ultrafine grain structure. J. Appl. Phys. 64, 6044 (1988).

5. A. Inoue, Y. Horio, Y.H. Kim, and T. Masumoto: Elevatedtemperature strength of an $\mathrm{Al}_{88} \mathrm{Ni}_{9} \mathrm{Ce}_{2} \mathrm{Fe}_{1}$ amorphous alloy containing nanoscale fcc-Al particles. Mater. Trans. JIM 33, 669 (1992).

6. A. Inoue, D. Kawase, A.P. Tsai, T. Zhang, and T. Masumoto: Stability and transformation to crystalline phases of amorphous $\mathrm{Zr}-\mathrm{Al}-\mathrm{Cu}$ alloys with significant supercooled liquid region. Mater. Sci. Eng., A 178, 255 (1994). 
7. B.S. Murty and K. Hono: Nanoquasicrystallization of Zr-based metallic glasses. Mater. Sci. Eng., A 312, 253 (2001).

8. A. Ishii, A. Iwase, Y. Fukumoto, Y. Yokoyama, T.J. Konno, and F. Hori: Effect of thermal annealing on the local structure in ZrCuAl bulk metallic glass. J. Alloys Compd 504, S230 (2010).

9. Q. Guo, J.H. Noh, P.K. Liaw, P.D. Rack, Y. Li, and C.V. Thompson: Density change upon crystallization of amorphous $\mathrm{Zr}-\mathrm{Cu}-\mathrm{Al}$ thin films. Acta Mater. 58, 3633 (2010).

10. J. Saida, M. Matsushita, C. Li, and A. Inoue: Formation of the icosahedral quasicrystalline phase in $\mathrm{Zr}_{70} \mathrm{Pd}_{30}$ binary glassy alloy. Philos. Mag. Lett. 81, 39 (2001).

11. K. Lu: Nanocrystalline metals crystallized from amorphous solids: Nanocrystallization, structure, and properties. Mater. Sci. Eng., $R$ 16, 161 (1996).

12. H. Chen, Y. He, G.J. Shiflet, and S.J. Poon: Deformation-induced nanocrystal formation in shear bands of amorphous alloys. Nature 367, 541 (1994).

13. T. Nagase, M. Nakamura, and Y. Umakoshi: Electron irradiation induced nano-crystallization in $\mathrm{Zr}_{66.7} \mathrm{Ni}_{33.3}$ amorphous alloy and $\mathrm{Zr}_{60} \mathrm{Al}_{15} \mathrm{Ni}_{25}$ metallic glass. Intermetallics 15, 211 (2007).

14. J. Saida, A.D. Setyawan, and E. Matsubara: Effect of relaxation state on nucleation and grain growth of nanoscale quasicrystal in Zr-based bulk metallic glasses prepared under various cooling rates. Appl. Phys. Lett. 99, 061903 (2011).

15. J.F. Loffler and W.L. Johnson: Model for decomposition and nanocrystallization of deeply undercooled $\mathrm{Zr}_{41.2} \mathrm{Ti}_{13.8} \mathrm{Cu}_{12.5} \mathrm{Ni}_{10} \mathrm{Be}_{22}$. Appl. Phys. Lett. 76, 3394 (2000).

16. G. He, Z. Bian, and G.L. Chen: Structures and properties of a Zr-based bulk glass alloy after annealing. Mater. Sci. Eng., A 270, 291 (1999).

17. X.L. Wang, J. Almer, C.T. Liu, Y.D. Wang, J.K. Zhao, A.D. Stoica, D.R. Haeffner, and W.H. Wang: In situ synchrotron study of phase transformation behaviors in bulk metallic glass by simultaneous diffraction and small angle scattering. Phys. Rev. Lett. 91, 265501 (2003).

18. D. Wang, H. Tan, and Y. Li: Multiple maxima of GFA in three adjacent eutectics in $\mathrm{Zr}-\mathrm{Cu}-\mathrm{Al}$ alloy system-A metallographic way to pinpoint the best glass forming alloys. Acta Mater. 53, 2969 (2006).
19. L. Yang, J.Z. Jiang, T. Liu, T.D. Hu, and T. Uruga: Atomic structure in $\mathrm{Zr}_{70} \mathrm{Cu}_{29} \mathrm{Pd}_{1}$ metallic glass. Appl. Phys. Lett. 87, 061918 (2005)

20. W.K. Luo, H.W. Sheng, F.M. Alamgir, J.M. Bai, J.H. He, and E. Ma: Icosahedral short-range order in amorphous alloys. Phys. Rev. Lett. 92, 145502 (2004).

21. L. Yang, S. Yin, X.D. Wang, Q.P. Cao, J.Z. Jiang, K. Saksl, and H. Franz: Atomic structure in $\mathrm{Zr}_{70} \mathrm{Ni}_{30}$ metallic glass. J. Appl. Phys. 102, 083512 (2007).

22. J.L. Finney: Modelling the structures of amorphous metal and alloys. Nature 266, 309 (1977)

23. V.S. Stepanyuk, A. Szasz, A.A. Katsnelson, O.S. Trushin, H. Müller, and H. Kirchmayr: Microstructure and its relaxation in $\mathrm{FeB}$ amorphous system simulated by moleculular dynamics. J. Non-Cryst. Solids 159, 80 (1993).

24. D.B. Miracle: A structural model for metallic glasses. Nat. Mater. 3, 697 (2004).

25. H.W. Sheng, W.K. Luo, F.M. Alamgir, J.M. Bai, and E. Ma: Atomic packing and short-to-medium-range order in metallic glasses. Nature 439, 419 (2006).

26. S. Zhang, T. Ichitsubo, Y. Yokoyama, T. Yamamoto, E. Matsubara, and $\mathrm{A}$. Inoue: Crystallization behavior and structural stability of $\mathrm{Zr}_{50} \mathrm{Cu}_{40} \mathrm{Al}_{10}$ bulk metallic glass. Mater. Trans. 50, 1340 (2009).

27. T. Yamamoto, Y. Yokoyama, T. Ichitsubo, H. Kimura, E. Matsubara, and $\mathrm{A}$. Inoue: Precipitation of the $\mathrm{ZrCu} B 2$ phase in $\mathrm{Zr}_{50} \mathrm{Cu}_{50-\mathrm{x}} \mathrm{Al}_{\mathrm{x}}(\mathrm{x}=0,4,6)$ metallic glasses by rapidly heating and cooling. J. Mater. Res. 25(4), 793 (2010).

28. L. Yang, J.H. Xia, Q. Wang, C. Dong, L.Y. Chen, X. Ou, J.F. Liu, J.Z. Jiang, K. Klementiev, K. Saksl, H. Franz, J.R. Schneider, and L. Gerward: Design of $\mathrm{Cu}_{8} \mathrm{Zr}_{5}$-based bulk metallic glasses. Appl. Phys. Lett. 88, 241913 (2006).

29. N.N. Medvedev and Y.I. Naberukhin: Shape of the Delaunay simplices in dense random packings of hard and soft spheres. J. Non-Cryst. Solids 94, 402 (1987).

30. L. Yang and G.Q. Guo: Preferred clusters in metallic glasses. Chin. Phys. B 12, 126101 (2010).

31. L. Yang, G.Q. Guo, L.Y. Chen, S.H. Wei, J.Z. Jiang, and X.D. Wang Atomic structure in Al-doped multicomponent bulk metallic glass. Scr. Mater. 63, 879 (2010). 